\section{PHYSICS IN WAR.}

Les Applications de la Physique pendant la Guerre. By H. Vigneron. Pp. viii +322 . (Paris: Masson et Cie, I919.) Price 7 francs net.

A BOOK with this title, appearing so soon A after the termination of hostilities, could scarcely fail to excite con siderable interest. The public in general and people with a scientific turn of mind in particular have been vaguely aware that, during the war, much work has been done in applying scientific principles to military purposes. In this country, as well as in Allied countries, there have been spread, in spite of the censorship, most exaggerated and distorted accounts of the practical results of these experiments. Here, then, in this book, it might have been supposed, would be afforded an opportunity of testing the truth of the rumours which have been current. To a reader in this frame of mind a perusal of the book will be somewhat disappointing. There are no great revelations, and it is a little difficult to see why the French censorship would not allow the author to publish the major portion of the contents during the war as he desired. The important subject of submarine detection and destruction, for example, is dealt with in a couple of pages. There is internal evidence that this does not arise from lack of knowledge on the part of the author, but rather from the operation of the censorship, which can have been removed in a very limited sense only. The author has, no doubt, been seriously handicapped in this way, for the French authorities appear to have been much more strict than our own.

M. Vigneron, in his preface, very properly lays stress on the important part played in the war by those men of science who, before the war, conducted speculative research without thought of the possibility of its practical application, and were forced by circumstances to join hands with the "techniciens," as he calls them. This alliance has produced far-reaching results, and there will be general agreement with the author that it should be fostered and perpetuated. The work of purely scientific workers is very liable to be lost sight of when it becomes absorbed in industry. One feels that M. Vigneron would have been able to do more justice to them had he delayed publication until it was permissible to refer more explicitly to their work. The author is evidently a believer in the practical fruits of pure science, and his advocacy of the methods of the General Electric Co. of Schenectady in this respect is sound.

The first of the seven sections of the present volume deals principally with the applications of optics for military purposes. Of particular interest are the chapters concerning rangefinders, and the many and varied uses of photography in warfare. One missẹs, however, any adequate reference to modern methods of signalling, such as those with infra-red and ultra-violet light, invented by Prof. R. W. Wood. Sections 2 and 3 are devoted, respectively, to the aerial and submarine aspects of war, and contain many interesting facts and diagrams. There is a long section on artillery and projectiles, containing much information, most of which was probably available before the war. The sixth section, on wireless telegraphy, is shorter than might have been expected, but gives an interesting outline of present methods, including the use of thermionic valves as oscillators and amplifiers. There is merely a mention of wireless telephony, which actually came into considerable practical use during the war. Localisation of foreign materials in the human body, mainly by means of X-rays. forms the subject of the last chapter.

The book is interesting and well written. It is illustrated with many good diagrams and photographic reproductions, which are explained clearly in the text. What is lacking with regard to "secret" developments the author will, we hope, take up in a subsequent volume.

EXPERIMENTAL RESEARCHES ON GLASS.

Experimental Researches Carried Out in the Department of Glass Technology, University of Sheffeld. Vol. i., I9I7-I8. (Reprinted from the Journal of the Society of Glass Technology.) Pp. iii +178 . (Sheffield: The University, n.d.)

$D^{R}$. W. E. S. TURNER is to be congratulated upon the success. which has attended the formation of the Department of Glass Technology, Sheffield University, of which he is the head, and of the Society of Glass Technology, of which he is secretary, and in the foundation of which he played a leading part. The results of the experimental researches carried out in the department are now reprinted from the journal of the society, together with certain reports to the council of the university.

Glass is a peculiarly elusive subject for scientific investigation, but neither man of science, technologist, nor practical worker will deny that it is a fascinating one. We know practically nothing about the nature of glass, and in this respect we are much in the position of the metallurgists prior to the introduction of thermal and micrographic methods of investigation. $\mathrm{W} e$ have as yet no key to the constitution of glass, and this must be sought in the purely scientific study of simple mixtures rather than in the investigation of complex glasses, which experience has proved to be practically useful.

At the beginning of the war very little information was available with regard even to the essential facts relating to scientific glassware, miners' lamps, and electric bulbs, which our glass manufacturers were called upon to supply with the least possible delay. Which was the best of the various brands of beakers and flasks at the moment in everyday use in chemical laboratories? was a question to which only the vaguest answer could be given. As to how these glasses should

$$
\text { No. 260I, VOL. 104] }
$$

